\title{
Por qué donar y cuánto donar: determinantes de la generosidad en el juego del dictador
}

\section{Why Donate, and How Much: Determinants of Generosity in the Dictator Game}

\author{
Antonio M. Espín* \\ Teresa García-Muñoz** \\ Universidad de Granada \\ Filippos Exadaktylos \\ ICTA, Universitat Autònoma de Barcelona***
}

\section{Resumen}

Este artículo estudia el papel de las características sociodemográficas y las preferencias sociales sobre el comportamiento generoso. Utilizando una muestra $(n=792)$ heterogénea representativa de la ciudad de Granada y el juego del dictador se investiga qué mecanismos trabajan sobre la decisión de donar dinero a otras personas anónimas y sobre la decisión de cuánto donar. Nuestros resultados indican que los determinantes que animan a participar (donar) son diferentes de los que llevan a aumentar la participación (donar más). Estos resultados pueden ser de gran interés para las organizaciones y actividades que se nutren de la participación voluntaria de terceros.

Palabras clave: juego del dictador, altruismo, preferencias sociales, donaciones, generosidad, experimento económico.

Clasificación JEL: C93, C91, C70.

\begin{abstract}
This paper studies the role of individuals' sociodemographic characteristics and social preferences on generous behaviour. Using a heterogeneous sample $(n=792)$, representative of Granada city and the dictator game, we investigate the mechanisms underlying the decision to donate money to other anonymous people and the decision of how much to donate. Our results indicate that the determinants that encourage an individual to participate (i.e. donate) and to increase participation (donate more) are different. These results may be of great interest for organizations and activities that need the voluntary participation of third parties.

Keywords: dictator game, altruism, social preferences, donations, generosity, economic experiments.

JEL Classification: C93, C91, C70.

* Departamento de Antropología Social, Universidad de Granada.

** Departamento de Métodos Cuantitativos. La autora agradece la financiación recibida por el Ministerio de Ciencia, Innovación y Universidades (PGC18-093506-B-I00).

*** Institut de Ciència i Tecnologia Ambientals-Institute of Environmental Science and Technology (ICTA, UAB).
\end{abstract}




\section{Introducción}

Uno de los resultados más consistentes que la economía del comportamiento ha puesto de manifiesto es que los individuos no solo se preocupan por su bienestar, también se interesan por el bienestar de los demás. Es decir, las personas, a la hora de tomar decisiones que pueden afectar a terceros, muestran preferencias sociales.

En el juego del dictador, un jugador ha de decidir cómo dividir una cierta cantidad de dinero con otro jugador en condiciones de completa libertad y anonimato. La predicción de la teoría económica «estándar» (donde la función de utilidad de los agentes considera únicamente el beneficio propio) es, obviamente, que el jugador que decide se queda con todo. Sin embargo, los resultados de múltiples experimentos muestran cómo una proporción no despreciable de sujetos es generosa: renuncia a una parte de sus ingresos para beneficiar a otros jugadores, desviándose así del mencionado «equilibrio» del juego. En Brañas-Garza et al. (2009) puede encontrarse una revisión de este tipo de experimentos y Engel (2011) presenta un meta-análisis de los resultados hasta la fecha.

Después de años de investigación, se tiene un conocimiento amplio sobre los entornos que hacen que los individuos se desvíen de forma sistemática del equilibrio en el juego del dictador, pero sabemos relativamente poco sobre cómo afectan las características personales de los individuos o sus preferencias sociales a esa desviación. Una de las razones principales de esta laguna tiene que ver con la homogeneidad de las muestras, mayoritariamente formadas por estudiantes, que se han utilizado en la mayoría de los experimentos. En este artículo, trataremos de arrojar luz sobre esta cuestión mediante el análisis del comportamiento de una población marcadamente heterogénea. A finales de 2010 nuestro grupo de investigación llevó a cabo un experimento de campo en el que se recogió una muestra representativa de la población adulta de la ciudad de Granada (España). El experimento consistió en una encuesta en la que se recogían, entre otros, datos socioeconómicos y sobre preferencias sociales y en la que, además, los sujetos encuestados realizaron varios juegos económicos experimentales, entre ellos el juego del dictador. La base de datos resultante de este experimento es mucho más heterogénea que la que se puede obtener con una muestra de estudiantes y nos va a permitir estudiar en profundidad el papel de las características personales sobre la generosidad en el juego del dictador.

Nuestra estrategia estadística se basa en analizar separadamente los determinantes de la decisión sobre si donar o no (es decir, de desviarse del equilibrio) y, una vez se decide donar, de la decisión sobre cuánto donar. Este aspecto novedoso de nuestro trabajo pone el foco en otra característica de las donaciones anónimas que se ha soslayado en la literatura: ¿la decisión de donar algo y la de cuánto donar tienen determinantes diferentes? (Engel, 2011). Esta no es una cuestión baladí y puede tener implicaciones importantes, por ejemplo, para las organizaciones de crowdfunding o de voluntariado. Entender qué factores son los que animan a las personas a participar de estas actividades y qué factores son los que les animan a aumentar su participación puede redundar en un aumento de la participación total y 
en una mejora de las perspectivas de los procesos que se nutren de las donaciones desinteresadas, de tiempo, dinero, u otros bienes y servicios, de terceros.

En la siguiente sección realizamos una breve revisión bibliográfica de trabajos que se han centrado en el estudio de los determinantes del comportamiento generoso en el juego del dictador. En la sección 3 se describen las variables utilizadas en el estudio. En la sección 4 presentamos el modelo econométrico empleado y los resultados encontrados. Finalizamos presentando las conclusiones en la sección 5.

\section{El juego del dictador}

El juego del dictador lo componen dos jugadores. El jugador 1 (dictador) es invitado a dividir una cantidad específica de dinero entre él y el jugador 2 (receptor). La decisión sobre el reparto la toma exclusivamente el dictador, mientras que el jugador 2 no tiene derecho a reclamar sobre la cantidad obtenida.

Según el principio de maximización del beneficio personal, la solución teórica del juego es simple: «el dictador se queda con todo, el receptor no recibe nada». Sin embargo, en los múltiples experimentos realizados del juego del dictador se observan sistemáticamente valores distintos de cero para la cantidad donada al jugador 2. En un meta-análisis sobre el juego del dictador realizado por Engel (2011) se encontró que el $36.11 \%$ de los dictadores no compartieron nada con los receptores, el $16.74 \%$ eligieron compartir la mitad y el $5.44 \%$ eligieron donar todo a los receptores. En experimentos estándar de laboratorio las donaciones oscilan entre cero y la mitad de la cantidad disponible a repartir. Un dictador típico transfiere un promedio de 20$30 \%$ y muy rara vez supera la mitad de la «tarta» (Camerer, 2003), aunque existen diferencias visibles entre culturas (Henrich et al., 2006, 2010).

Pero, ¿qué mueve a los individuos a comportarse de forma generosa? Considerando que cualquier donación positiva se puede interpretar como una muestra de generosidad, el juego del dictador es un mecanismo cuasi-perfecto para estudiar el comportamiento generoso: es un juego simple donde los jugadores no se enfrentan a complejos problemas de maximización, además no hay espacio para la reciprocidad ni para cualquier otra motivación estratégica. A continuación se resumen algunas de las investigaciones realizadas para tratar de comprender por qué los sujetos se desvían sistemáticamente del equilibrio (donación $=0$ ).

En primer lugar, resaltamos una serie de trabajos que realizan nuevos diseños del juego incorporando información sobre el receptor. Ejemplos de estos tratamientos son Eckel y Grossman (1998), donde el jugador 2 es la Cruz Roja de la localidad; Burnham (2003), que proporciona fotografías de los receptores a los dictadores; Charness y Gneezy (2001), que proporcionan a los dictadores los apellidos del receptor; Brañas-Garza (2006), donde se les informa que los receptores son africanos y que recibirán el dinero en forma de medicinas; y Frohlich et al. (2001), donde los dictadores pueden ver a los receptores un momento antes del experimento. En todos estos trabajos se ha encontrado que la falta de anonimato disminuye el número 
de sujetos completamente egoístas (donación $=0$ ) e incrementa el porcentaje de individuos generosos con el receptor. Hoffman et al. (1996) proponen una serie de tratamientos alternativos que van sistemáticamente aislando al sujeto experimental (aumentando el anonimato), y generando así «distancia social». Esta distancia puede hacer que el sujeto se sienta más libre para llevar a cabo la acción que considere oportuna sin tener que soportar el coste de ser reconocido como egoísta. Como resultado, las transferencias de los dictadores en los experimentos se van reduciendo a medida que el grado de anonimato aumenta.

Otra línea de investigación ha puesto de manifiesto la relación existente entre el comportamiento altruista y el capital social (el grado de integración social) de los individuos. Como muestran Brañas-Garza et al. (2010): i) los sujetos menos altruistas (los que no donan nada en el juego del dictador) suelen tener un papel poco importante en la red social (tienen menos conexiones en la red social, son menos centrales) y ii) los sujetos con gran capital social (los más centrales) son más altruistas y, además, más aversos a la desigualdad (Brañas-Garza et al., 2012).

Como hemos visto, gran parte de los esfuerzos por comprender por qué los sujetos se desvían sistemáticamente del equilibrio se han centrado en los efectos de diversos tratamientos en lugar de en el análisis de cómo las características personales pueden influir en el comportamiento. Por tanto, no es sorprendente que después de muchos años de intensa investigación sepamos muy poco acerca de la interrelación entre las características personales y las donaciones en el juego del dictador -con pocas excepciones, como es el género, donde existen resultados no concluyentes (Croson y Gneezy, 2009), aunque con tendencia a observarse una mayor generosidad de las mujeres (Brañas-Garza et al., 2018) - . Este es el objetivo del trabajo, estudiar qué características personales están relacionadas con el comportamiento generoso. La heterogeneidad y representatividad de los datos utilizados nos ofrecen la oportunidad de obtener resultados robustos y generalizables.

\section{Variables en el estudio}

Como se ha comentado, a finales de 2010 se llevó a cabo la recogida de una muestra representativa de la población adulta de la ciudad de Granada mediante muestreo aleatorio estratificado por distritos con afijación proporcional. Un total de 216 estudiantes universitarios, agrupados en 108 parejas, realizaron la recogida de datos en los domicilios resultantes del proceso de muestreo. Estos estudiantes estaban matriculados en un curso sobre experimentos de campo que se llevó a cabo en otoño de 2010 en la Facultad de Ciencias Económicas y Empresariales de la Universidad de Granada. Con antelación a la recogida de datos los estudiantes tuvieron 10 horas de formación sobre metodología de realización de experimentos de campo, encuestas y procedimientos de muestreo. La recogida de datos formó parte de su formación y evaluación en el curso. Los estudiantes no recibieron ninguna prestación monetaria. El proceso fue controlado en tiempo real por los investigadores principales mediante 
(i) una plataforma web creada al efecto donde los encuestadores debían reportar los datos a medida que se iban recogiendo y (ii) llamadas telefónicas a encuestados elegidos aleatoriamente.

La muestra inicial estaba formada por un total de 835 individuos con edades comprendidas entre los 16 y los 91 años de edad (para más información sobre la muestra y la recogida de datos, ver Exadaktylos et al., 2013). El tamaño muestral se ha reducido en este estudio por los valores perdidos encontrados en algunas de las variables. De esta forma, la muestra utilizada en el estudio la forman 792 individuos.

Los sujetos encuestados contestaron un amplio cuestionario con preguntas sociodemográficas, de capital social y sobre preferencias sociales. En la última parte de la encuesta realizaron tres juegos experimentales con dinero real; uno de ellos fue el juego del dictador (los otros juegos fueron el ultimátum y el juego de la confianza; ver Exadaktylos et al., 2013). Los juegos se realizaron bajo condiciones de anonimato: los participantes respondían marcando sus decisiones en una hoja sin ser vistos por los encuestadores, luego la introducían en un sobre y finalmente lo cerraban. Una vez recogidos todos los datos, los participantes fueron emparejados aleatoriamente de forma anónima para calcular los pagos resultantes de los juegos. Uno de cada 10 participantes fue seleccionado aleatoriamente para recibir el pago correspondiente a uno de los juegos, elegido también aleatoriamente. Como es típico en los experimentos económicos, toda esta información era conocida por los participantes antes de tomar sus decisiones.

\subsection{Variable dependiente: donaciones}

El enunciado del juego del dictador era:

«En esta decisión te damos 20 euros para que los repartas entre la otra persona y tú. De estos 20 euros, tú puedes mandarle a esa persona la parte que tú quieras, es decir, puedes no mandarle nada, todo o mandarle una parte. Obviamente, la parte que no le envíes es directamente para ti. ¿Qué cantidad le envías a esa persona?: tienes que rodear con un círculo el número de euros que le MANDAS a la otra persona en la casilla que está en AZUL, solo pueden ser números pares $(0,2,4, \ldots, 20) »$.

Como vemos, el participante debía tomar una decisión dentro de un rango de 11 posibilidades (unidad de medida $=2$ euros). La donación media de los 792 individuos incluidos en el estudio fue de 7,87 euros (sobre 20, esto es, un 39\%) con una desviación típica de 4,35 euros. El Gráfico 1 muestra la distribución de las donaciones. 


\section{GRÁFICO 1 \\ DISTRIBUCIÓN DE DONACIONES EN EL JUEGO DEL DICTADOR}

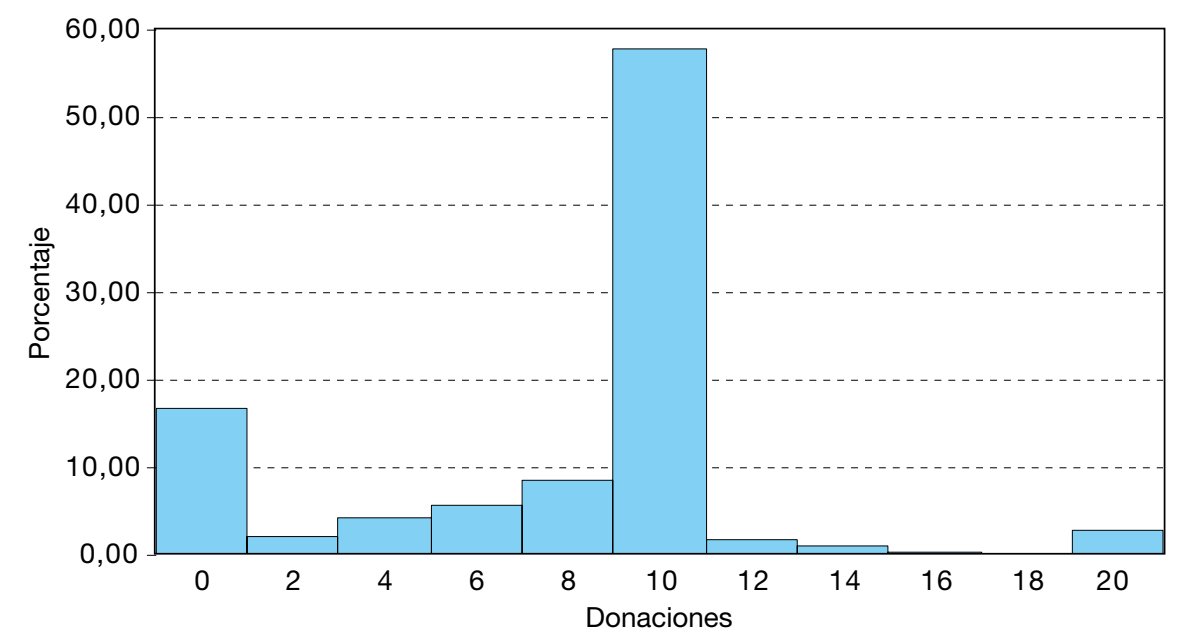

FUENTE: Elaboración propia.

Como podemos observar, la situación más habitual es el reparto igualitario (10 euros; $57,83 \%$ de los participantes), siendo la segunda donación más frecuente la de 0 euros $(16,54 \%)$. Comparándolos con los resultados mencionados en la introducción (obtenidos mayoritariamente usando muestras de estudiantes universitarios), nuestros participantes muestran un comportamiento relativamente generoso, lo que es habitual en experimentos de campo como el nuestro (ver, por ejemplo, Henrich et al., 2006, 2010).

\subsection{Variables explicativas}

En esta sección se presentan las variables explicativas incluidas en el estudio. Se han distinguido tres grupos de variables: sociodemográficas, sobre preferencias sociales y de capital social.

\subsubsection{Variables sociodemográficas}

Las variables sociodemográficas utilizadas son:

- Edad, como variable continua, y su cuadrado para tener en cuenta posibles efectos no lineales.

- Hombre, variable dicotómica que toma el valor 1 si el individuo es hombre, 0 en otro caso.

- Estado civil, variable categórica dividida en: soltero/a (categoría de referencia), casado/a o conviviendo en pareja, divorciado/a o separado/a y viudo/a. 
- Hijos, variable dicotómica que toma el valor 1 si el individuo tiene hijos, 0 en otro caso.

- Educación, variable categórica con 4 categorías: sin estudios (categoría de referencia), con estudios primarios, con estudios secundarios, con estudios universitarios.

- Situación laboral, variable categórica con 5 categorías: desempleado/a, trabajador/a por cuenta ajena (categoría de referencia), trabajador/a del sector público, trabajador/a por cuenta ajena, pensionista.

- No creyente, variable dicotómica que toma el valor 1 si el individuo es no creyente (religión), 0 en otro caso.

- Ingresos del hogar, variable categórica con cuatro categorías correspondientes a los cuatro cuartiles en los que se divide la muestra según los ingresos del hogar. La categoría de referencia es el cuarto cuartil, que incluye a las familias con mayores ingresos.

- Contribución alta, variable dicotómica que toma el valor 1 si el individuo contribuye al menos a la mitad del total de ingresos del hogar, 0 en otro caso.

\subsubsection{Preferencias sociales}

Decimos que un sujeto tiene preferencias sociales cuando a la hora de maximizar su bienestar subjetivo (su utilidad), además de sus propios beneficios, tiene en cuenta los beneficios de los demás. Una definición más formal se puede encontrar en Fehr y Fischbacher (2002): «Una persona exhibe preferencias sociales cuando no solo se preocupa por los recursos que le son asignados, sino que también toma en consideración los recursos asignados a agentes de referencia relevantes para él» ${ }^{1}$. Algunas de las preferencias sociales que estos autores destacan, y para las que disponemos de medidas en nuestra encuesta, son:

- Aversión a la desigualdad: se presenta cuando el individuo quiere lograr una distribución igualitaria de los recursos. Esto significa que, por un lado, los individuos con aversión a la desigualdad son altruistas y desearán incrementar los beneficios de los otros cuando estos están por debajo de lo que se considera equitativo. Y, por otro lado, también sienten envidia y estarán motivados por reducir los beneficios de los otros cuando consideran que exceden el punto equitativo. Siguiendo el modelo de Fehr-Schmidt (1999) diseñamos dos preguntas sobre aversión a la desigualdad. En ellas se pide al individuo que valore las siguientes afirmaciones en una escala de 1 a 7 donde 1 significa totalmente en desacuerdo, 7 totalmente de acuerdo y el punto neutral es el 4:

Aversión a la desigualdad $\alpha$ del modelo de Fehr-Schmidt (Envidia): «No me preocupa cuánto dinero tengo, lo que me preocupa es que otros tienen más que yo».

\footnotetext{
${ }^{1}$ Traducción propia.
} 
Aversión a la desigualdad $\beta$ del modelo de Fehr-Schmidt (Compasión): «No me preocupa cuánto dinero tengo, lo que me preocupa es que otros tienen menos que yo». Según nuestro conocimiento, estas preguntas sobre aversión a la desigualdad (basadas en el modelo Fehr-Schmidt) se incluyen en un cuestionario por primera vez en esta encuesta. Espín et al. (2018) presentan el primer análisis publicado sobre estas medidas, mostrando que la envidia correlaciona negativamente y la compasión positivamente con la satisfacción con la vida de los individuos. Brañas-Garza et al. (2020) presenta un análisis más detallado de estas medidas.

- Reciprocidad: un individuo recíproco responde de forma amable ante acciones amables (reciprocidad positiva) y de forma hostil ante acciones hostiles (reciprocidad negativa). Para medir las reciprocidades positiva y negativa utilizamos dos preguntas del cuestionario en las que se pedía responder si se estaba de acuerdo o no con las siguientes afirmaciones en la misma escala de 1 a 7.

Reciprocidad negativa: «Soy amable y simpático sólo si los demás se comportan bien conmigo, de lo contrario: ojo por ojo».

Reciprocidad positiva: «Si alguien me hace el favor de prestarme dinero, siento que debería devolverle algo más de lo prestado».

Estas preguntas sobre reciprocidad se han obtenido del cuestionario Personal Norm of Reciprocity desarrollado por Perugini et al. (2003).

- Altruismo: es una forma incondicional de bondad. Se presenta cuando el individuo valora positivamente los recursos de los otros independientemente de «si se lo merecen» o no. Un individuo altruista nunca emprenderá una acción que haga decrecer el pago de otras personas. Para medir el altruismo incondicional se preguntó al individuo que valorase en la misma escala de 1 a 7 la siguiente afirmación: «Ayudaría a un conocido que sé que no lo haría por mí».

\subsubsection{Variables de capital social}

Como medidas del capital social se han elegido dos cuestiones que aparecen en la World Values Survey y que representan la opinión que tienen los sujetos entrevistados sobre la gente que les rodea:

- Confianza, es una variable dicotómica que responde a la siguiente pregunta: «En general, ¿crees que se puede tener confianza en la mayoría de la gente, $o$ que se debe ser muy prudente al relacionarse con la gente?». La variable toma el valor 1 si la respuesta es «Se puede tener confianza en la mayoría de la gente» y el valor 0 si es «Se debe ser muy prudente al relacionarse con la gente».

- Justicia, es una variable dicotómica basada en la siguiente cuestión: «¿Crees que la mayoría de la gente intentaría aprovecharse de ti, si tuvieran la oportunidad, o tratarían de ser justos?». La variable toma el valor 1 si el entrevistado responde «La mayoría de la gente trataría de ser justa» y el valor 0 si contesta «La mayoría de la gente intentaría aprovecharse de ti».

2 www.worldvaluessurvey.com 
Los estadísticos descriptivos de todas las variables utilizadas en el estudio se encuentran en el Cuadro 1.

\section{CUADRO 1}

ESTADÍSTICOS DESCRIPTIVOS DE LAS VARIABLES (n = 792)

\begin{tabular}{|c|c|c|c|c|}
\hline Variable & Media & Desv. típica & Min & Max \\
\hline Donación & 7,871 & 4,354 & 0 & 20 \\
\hline \multicolumn{5}{|l|}{ Variables sociodemográficas } \\
\hline Edad & 37,841 & 17,158 & 16 & 89 \\
\hline Hombre & 0,458 & 0,499 & 0 & 1 \\
\hline \multicolumn{5}{|l|}{ Estado civil } \\
\hline Soltero & 0,511 & 0,250 & 0 & 1 \\
\hline Casado o conviviendo & 0,404 & 0,491 & 0 & 1 \\
\hline Divorciado o separado & 0,042 & 0,200 & 0 & 1 \\
\hline Viudo & 0,043 & 0,203 & 0 & 1 \\
\hline Hijos & 0,446 & 0,497 & 0 & 1 \\
\hline \multicolumn{5}{|l|}{ Educación } \\
\hline Sin educación & 0,038 & 0,037 & 0 & 1 \\
\hline Primaria & 0,109 & 0,311 & 0 & 1 \\
\hline Secundaria & 0,306 & 0,461 & 0 & 1 \\
\hline Universidad & 0,547 & 0,498 & 0 & 1 \\
\hline \multicolumn{5}{|l|}{ Estado laboral } \\
\hline Trabajador por cuenta ajena & 0,207 & 0,164 & 0 & 1 \\
\hline Desempleado & 0,472 & 0,500 & 0 & 1 \\
\hline Trabajador del sector público & 0,128 & 0,334 & 0 & 1 \\
\hline Trabajador por cuenta propia & 0,081 & 0,273 & 0 & 1 \\
\hline Pensionista & 0,112 & 0,316 & 0 & 1 \\
\hline \multicolumn{5}{|l|}{ Ingresos } \\
\hline Primer cuartil & 0,330 & 0,470 & 0 & 1 \\
\hline Segundo cuartil & 0,176 & 0,381 & 0 & 1 \\
\hline Tercer cuartil & 0,254 & 0,435 & 0 & 1 \\
\hline Cuarto cuartil & 0,240 & 0,182 & 0 & 1 \\
\hline Contribución alta & 0,426 & 0,495 & 0 & 1 \\
\hline No creyente & 0,312 & 0,464 & 0 & 1 \\
\hline \multicolumn{5}{|l|}{ Variables preferencias sociales } \\
\hline Envidia & 2,433 & 1,787 & 1 & 7 \\
\hline Compasión & 4,073 & 2,055 & 1 & 7 \\
\hline Reciprocidad positiva & 3,612 & 2,266 & 1 & 7 \\
\hline Reciprocidad negativa & 3,808 & 2,158 & 1 & 7 \\
\hline Altruismo & 4,843 & 1,911 & 1 & 7 \\
\hline \multicolumn{5}{|l|}{ Variable capital social } \\
\hline Confianza & 0,246 & 0,431 & 0 & 1 \\
\hline Justicia & 0,455 & 0,498 & 0 & 1 \\
\hline
\end{tabular}

FUENTE: Elaboración propia. 


\section{Modelo econométrico y resultados}

A la hora de estudiar el comportamiento generoso a través del juego del dictador se debe tener en cuenta el proceso de decisión al que se enfrenta el sujeto. Tal vez el estudio de los determinantes de la cantidad donada no sea el camino correcto a seguir dado que habrá un alto porcentaje de sujetos que no estén dispuestos a donar nada bajo ninguna circunstancia. Parece más coherente que el proceso de decisión se lleve a cabo en dos pasos: primero los individuos deciden si donar o no, y una vez que han decidido donar eligen qué cantidad de dinero dar. Para explorar esta posibilidad se han utilizado modelos Hurdle (Cragg, 1971; Moffat, 2016). Estos modelos permiten que las decisiones sobre donar y sobre qué cantidad donar se originen por mecanismos diferentes, permitiendo así distintos determinantes. En primer lugar, se estudian los determinantes de que el sujeto decida donar algo mediante una regresión probit y, en una segunda etapa, sabiendo que el individuo ha decidido donar se estudian qué características determinan la cantidad donada mediante un modelo de regresión normal truncado.

Los resultados se muestran en los Cuadros 2 y 3 . En el Cuadro 2 se presentan los determinantes que están asociados a la decisión de donar y en el Cuadro 3 los determinantes de la cantidad donada, una vez que el sujeto decide donar. En ambos cuadros aparecen cinco modelos en sendas columnas. En el modelo (1) se consideran solo las variables sociodemográficas, mientras que en los modelos (2-4) se incluyen sucesivamente las tres preferencias sociales consideradas (aversión a la desigualdad, reciprocidad y altruismo) y en el último modelo se analizan también las variables de capital social.

El primer resultado a resaltar es, como se verá a continuación, que los factores asociados a la decisión de donar y a la cantidad donada no son los mismos.

Comenzamos comentando los resultados encontrados para el modelo que describe la decisión de donar en el juego del dictador (Cuadro 2).

En relación a las variables sociodemográficas, se observa que los hombres muestran menor probabilidad de decidir donar (aunque solo cuando no se controla el altruismo ni las variables de capital social). Por otro lado, es más probable que los divorciados/as decidan donar en comparación con los solteros. También se observa que los individuos de familias con menores ingresos están más predispuestos a donar; concretamente las familias en los cuartiles 1 y 3 (no significativo para el cuartil 2) tienen mayor probabilidad de realizar una donación positiva en comparación con las familias en el cuartil más alto (familias más ricas). Este resultado es cercano al encontrado por Erkal et al. (2011) donde comprobaron que los individuos con ingresos más altos eran más reacios a donar que los individuos con ingresos moderados. Por último, una mayor aportación a los ingresos del hogar es un determinante positivo a la hora de decidir donar, pero solo cuando no se tienen en cuenta ni el altruismo y ni las variables de capital social. 


\section{CUADRO 2}

PRIMERA ETAPA DEL MODELO HURDLE: DETERMINANTES DE LA DECISIÓN DE DONAR

\begin{tabular}{|c|c|c|c|c|c|}
\hline Variables & (1) & (2) & (3) & (4) & (5) \\
\hline \multicolumn{6}{|l|}{ Variables sociodemográficas } \\
\hline Edad & $\begin{array}{l}-0,024 \\
(0,024)\end{array}$ & $\begin{array}{l}-0,024 \\
(0,024)\end{array}$ & $\begin{array}{l}-0,030 \\
(0,024)\end{array}$ & $\begin{array}{l}-0,029 \\
(0,024)\end{array}$ & $\begin{array}{l}-0,031 \\
(0,024)\end{array}$ \\
\hline Edad al cuadrado & $\begin{array}{c}0,0002 \\
(0,0003)\end{array}$ & $\begin{array}{c}0,0002 \\
(0,0003)\end{array}$ & $\begin{array}{c}0,0003 \\
(0,0002)\end{array}$ & $\begin{array}{c}0,0003 \\
(0,0002)\end{array}$ & $\begin{array}{c}0,0003 \\
(0,0002)\end{array}$ \\
\hline Hombre & $\begin{array}{c}-0,261 * * \\
(0,123)\end{array}$ & $\begin{array}{c}-0,218^{*} \\
(0,122)\end{array}$ & $\begin{array}{l}-0,187 \\
(0,122)\end{array}$ & $\begin{array}{l}-0,170 \\
(0,122)\end{array}$ & $\begin{array}{l}-0,181 \\
(0,121)\end{array}$ \\
\hline \multicolumn{6}{|l|}{ Estado civil } \\
\hline Soltero & ref. & ref. & ref. & ref. & ref. \\
\hline Casado o conviviendo & $\begin{array}{c}0,057 \\
(0,221)\end{array}$ & $\begin{array}{c}0,037 \\
(0,222)\end{array}$ & $\begin{array}{c}0,045 \\
(0,228)\end{array}$ & $\begin{array}{c}0,061 \\
(0,224)\end{array}$ & $\begin{array}{c}0,052 \\
(0,227)\end{array}$ \\
\hline Divorciado o separado & $\begin{array}{c}0,842 * * \\
(0,428)\end{array}$ & $\begin{array}{c}0,832 * \\
(0,439)\end{array}$ & $\begin{array}{c}0,857 * * \\
(0,423)\end{array}$ & $\begin{array}{l}0,819 * \\
(0,422)\end{array}$ & $\begin{array}{l}0,766^{*} \\
(0,420)\end{array}$ \\
\hline Viudo & $\begin{array}{l}-0,295 \\
(0,353)\end{array}$ & $\begin{array}{c}-0,324 \\
(0,370)\end{array}$ & $\begin{array}{l}-0,344 \\
(0,372)\end{array}$ & $\begin{array}{l}-0,374 \\
(0,373)\end{array}$ & $\begin{array}{l}-0,396 \\
(0,375)\end{array}$ \\
\hline Hijos & $\begin{array}{c}0,216 \\
(0,180)\end{array}$ & $\begin{array}{c}0,247 \\
(0,183)\end{array}$ & $\begin{array}{c}0,256 \\
(0,179)\end{array}$ & $\begin{array}{c}0,252 \\
(0,182)\end{array}$ & $\begin{array}{c}0,252 \\
(0,183)\end{array}$ \\
\hline \multicolumn{6}{|l|}{ Educación } \\
\hline Sin educación & ref. & ref. & ref. & ref. & ref. \\
\hline Primaria & $\begin{array}{c}0,597 \\
(0,373)\end{array}$ & $\begin{array}{c}0,588 \\
(0,374)\end{array}$ & $\begin{array}{c}0,597 \\
(0,391)\end{array}$ & $\begin{array}{c}0,546 \\
(0,380)\end{array}$ & $\begin{array}{c}0,546 \\
(0,376)\end{array}$ \\
\hline Secundaria & $\begin{array}{c}0,444 \\
(0,342)\end{array}$ & $\begin{array}{c}0,407 \\
(0,349)\end{array}$ & $\begin{array}{c}0,368 \\
(0,362)\end{array}$ & $\begin{array}{c}0,326 \\
(0,360)\end{array}$ & $\begin{array}{c}0,300 \\
(0,366)\end{array}$ \\
\hline Universidad & $\begin{array}{c}0,401 \\
(0,343)\end{array}$ & $\begin{array}{c}0,373 \\
(0,351)\end{array}$ & $\begin{array}{c}0,306 \\
(0,362)\end{array}$ & $\begin{array}{c}0,267 \\
(0,355)\end{array}$ & $\begin{array}{c}0,222 \\
(0,357)\end{array}$ \\
\hline \multicolumn{6}{|l|}{ Estado laboral } \\
\hline Trabajador por cuenta ajena & ref. & ref. & ref. & ref. & ref. \\
\hline Desempleado & $\begin{array}{c}0,045 \\
(0,146)\end{array}$ & $\begin{array}{c}0,044 \\
(0,146)\end{array}$ & $\begin{array}{c}0,035 \\
(0,146)\end{array}$ & $\begin{array}{l}-0,005 \\
(0,152)\end{array}$ & $\begin{array}{c}0,006 \\
(0,154)\end{array}$ \\
\hline Trabajador del sector público & $\begin{array}{c}0,256 \\
(0,193)\end{array}$ & $\begin{array}{c}0,226 \\
(0,199)\end{array}$ & $\begin{array}{c}0,181 \\
(0,209)\end{array}$ & $\begin{array}{c}0,164 \\
(0,209)\end{array}$ & $\begin{array}{c}0,175 \\
(0,207)\end{array}$ \\
\hline Trabajador por cuenta propia & $\begin{array}{c}0,279 \\
(0,232)\end{array}$ & $\begin{array}{c}0,219 \\
(0,226)\end{array}$ & $\begin{array}{c}0,203 \\
(0,229)\end{array}$ & $\begin{array}{c}0,183 \\
(0,227)\end{array}$ & $\begin{array}{c}0,170 \\
(0,229)\end{array}$ \\
\hline
\end{tabular}


CUADRO 2 (Continuación)

PRIMERA ETAPA DEL MODELO HURDLE: DETERMINANTES DE LA DECISIÓN DE DONAR

\begin{tabular}{|c|c|c|c|c|c|}
\hline Variables & (1) & (2) & (3) & (4) & (5) \\
\hline Pensionista & $\begin{array}{c}0,116 \\
(0,356)\end{array}$ & $\begin{array}{c}0,061 \\
(0,354)\end{array}$ & $\begin{array}{c}0,014 \\
(0,343)\end{array}$ & $\begin{array}{c}0,003 \\
(0,337)\end{array}$ & $\begin{array}{c}0,019 \\
(0,324)\end{array}$ \\
\hline \multicolumn{6}{|l|}{ Ingresos } \\
\hline Primer cuartil & $\begin{array}{c}0,435 * * * \\
(0,166)\end{array}$ & $\begin{array}{c}0,450 * * * \\
(0,167)\end{array}$ & $\begin{array}{c}0,465 * * * \\
(0,165)\end{array}$ & $\begin{array}{c}0,502^{* * *} \\
(0,169)\end{array}$ & $\begin{array}{c}0,506 * * * \\
(0,170)\end{array}$ \\
\hline Segundo cuartil & $\begin{array}{c}0,216 \\
(0,195)\end{array}$ & $\begin{array}{c}0,232 \\
(0,196)\end{array}$ & $\begin{array}{c}0,242 \\
(0,195)\end{array}$ & $\begin{array}{c}0,241 \\
(0,195)\end{array}$ & $\begin{array}{c}0,221 \\
(0,196)\end{array}$ \\
\hline Tercer cuartil & $\begin{array}{c}0,386 * * \\
(0,178)\end{array}$ & $\begin{array}{c}0,409 * * \\
(0,178)\end{array}$ & $\begin{array}{c}0,424 * * \\
(0,177)\end{array}$ & $\begin{array}{c}0,430 * * \\
(0,179)\end{array}$ & $\begin{array}{c}0,430 * * \\
(0,179)\end{array}$ \\
\hline Cuarto cuartil & ref. & ref. & ref. & ref. & ref. \\
\hline Contribución alta & $\begin{array}{l}0,219 * \\
(0,124) \\
\end{array}$ & $\begin{array}{l}0,207 * \\
(0,122) \\
\end{array}$ & $\begin{array}{l}0,201^{*} \\
(0,120) \\
\end{array}$ & $\begin{array}{c}0,167 \\
(0,120) \\
\end{array}$ & $\begin{array}{c}0,177 \\
(0,123) \\
\end{array}$ \\
\hline No creyente & $\begin{array}{l}-0,180 \\
(0,129)\end{array}$ & $\begin{array}{l}-0,182 \\
(0,134)\end{array}$ & $\begin{array}{l}-0,194 \\
(0,131)\end{array}$ & $\begin{array}{l}-0,168 \\
(0,131)\end{array}$ & $\begin{array}{l}-0,197 \\
(0,130)\end{array}$ \\
\hline \multicolumn{6}{|c|}{ Variables preferencias sociales } \\
\hline Envidia & & $\begin{array}{c}-0,047 * \\
(0,027)\end{array}$ & $\begin{array}{l}-0,039 \\
(0,027) \\
\end{array}$ & $\begin{array}{l}-0,034 \\
(0,027) \\
\end{array}$ & $\begin{array}{l}-0,039 \\
(0,027)\end{array}$ \\
\hline Compasión & & $\begin{array}{c}0,095 * * * \\
(0,035)\end{array}$ & $\begin{array}{c}0,090 * * * \\
(0,035)\end{array}$ & $\begin{array}{c}0,077 * * \\
(0,035)\end{array}$ & $\begin{array}{c}0,073 * * \\
(0,036)\end{array}$ \\
\hline Reciprocidad positiva & & & $\begin{array}{c}0,038 \\
(0,028)\end{array}$ & $\begin{array}{c}0,026 \\
(0,029)\end{array}$ & $\begin{array}{c}0,029 \\
(0,029)\end{array}$ \\
\hline Reciprocidad negativa & & & $\begin{array}{c}-0,081 * * * \\
(0,027) \\
\end{array}$ & $\begin{array}{c}-0,068 * * \\
(0,027) \\
\end{array}$ & $\begin{array}{c}-0,062 * * \\
(0,028)\end{array}$ \\
\hline Altruismo & & & & $\begin{array}{c}0,083 * * * \\
(0,031)\end{array}$ & $\begin{array}{c}0,080 * * \\
(0,031)\end{array}$ \\
\hline \multicolumn{6}{|l|}{ Variable de capital social } \\
\hline Confianza & & & & & $\begin{array}{c}0,036 \\
(0,133) \\
\end{array}$ \\
\hline Justicia & & & & & $\begin{array}{c}0,269 * * \\
(0,117)\end{array}$ \\
\hline Constante & $\begin{array}{c}0,682 \\
(0,518) \\
\end{array}$ & $\begin{array}{c}0,489 \\
(0,569) \\
\end{array}$ & $\begin{array}{c}0,863 \\
(0,605) \\
\end{array}$ & $\begin{array}{c}0,536 \\
(0,627) \\
\end{array}$ & $\begin{array}{c}0,505 \\
(0,634) \\
\end{array}$ \\
\hline Observaciones & 792 & 792 & 792 & 792 & 792 \\
\hline
\end{tabular}

NOTA: Errores robustos entre paréntesis. $* * * p<0.01 . * * p<0.05 . * p<0.1$.

FUENTE: Elaboración propia. 


\section{CUADRO 3}

SEGUNDA ETAPA DEL MODELO HURDLE: DETERMINANTES DE LA CANTIDAD DONADA (ENTRE QUIENES DONAN)

\begin{tabular}{|c|c|c|c|c|c|}
\hline Variables & (1) & (2) & (3) & (4) & (5) \\
\hline \multicolumn{6}{|l|}{ Variables sociodemográficas } \\
\hline Edad & $\begin{array}{c}0,096 * * \\
(0,044)\end{array}$ & $\begin{array}{c}0,094 * * \\
(0,044)\end{array}$ & $\begin{array}{l}0,085^{*} \\
(0,044)\end{array}$ & $\begin{array}{l}0,085^{*} \\
(0,044)\end{array}$ & $\begin{array}{c}0,089 * * \\
(0,042)\end{array}$ \\
\hline Edad al cuadrado & $\begin{array}{c}-0,0009 * * \\
(0,0004)\end{array}$ & $\begin{array}{c}-0,0009 * * \\
(0,0004)\end{array}$ & $\begin{array}{c}-0,0008^{* *} \\
(0,0004)\end{array}$ & $\begin{array}{c}-0,0008 * * \\
(0,0004)\end{array}$ & $\begin{array}{c}-0,0009 * * \\
(0,0004)\end{array}$ \\
\hline Hombre & $\begin{array}{l}0,382 * \\
(0,218)\end{array}$ & $\begin{array}{l}0,418^{*} \\
(0,218)\end{array}$ & $\begin{array}{c}0,459 * * \\
(0,218)\end{array}$ & $\begin{array}{c}0,460 * * \\
(0,218)\end{array}$ & $\begin{array}{c}0,459 * * \\
(0,220)\end{array}$ \\
\hline \multicolumn{6}{|l|}{ Estado civil } \\
\hline Soltero & ref. & ref. & ref. & ref. & ref. \\
\hline Casado o conviviendo & $\begin{array}{l}-0,031 \\
(0,459)\end{array}$ & $\begin{array}{l}-0,075 \\
(0,460)\end{array}$ & $\begin{array}{l}-0,079 \\
(0,464)\end{array}$ & $\begin{array}{l}-0,076 \\
(0,466)\end{array}$ & $\begin{array}{l}-0,065 \\
(0,469)\end{array}$ \\
\hline Divorciado o separado & $\begin{array}{c}0,202 \\
(0,589)\end{array}$ & $\begin{array}{c}0,208 \\
(0,578)\end{array}$ & $\begin{array}{c}0,167 \\
(0,580)\end{array}$ & $\begin{array}{c}0,172 \\
(0,577)\end{array}$ & $\begin{array}{c}0,206 \\
(0,592)\end{array}$ \\
\hline Viudo & $\begin{array}{l}-0,357 \\
(0,519)\end{array}$ & $\begin{array}{l}-0,413 \\
(0,511)\end{array}$ & $\begin{array}{l}-0,486 \\
(0,517)\end{array}$ & $\begin{array}{l}-0,485 \\
(0,517)\end{array}$ & $\begin{array}{c}-0,510 \\
(0,510)\end{array}$ \\
\hline Hijos & $\begin{array}{c}0,301 \\
(0,384)\end{array}$ & $\begin{array}{c}0,309 \\
(0,387)\end{array}$ & $\begin{array}{c}0,298 \\
(0,390)\end{array}$ & $\begin{array}{c}0,298 \\
(0,389)\end{array}$ & $\begin{array}{c}0,246 \\
(0,388)\end{array}$ \\
\hline \multicolumn{6}{|l|}{ Educación } \\
\hline Sin educación & ref. & ref. & ref. & ref. & ref. \\
\hline Primaria & $\begin{array}{c}0,689 \\
(0,699)\end{array}$ & $\begin{array}{c}0,586 \\
(0,685)\end{array}$ & $\begin{array}{c}0,592 \\
(0,673)\end{array}$ & $\begin{array}{c}0,591 \\
(0,672)\end{array}$ & $\begin{array}{c}0,563 \\
(0,668)\end{array}$ \\
\hline Secundaria & $\begin{array}{c}0,859 \\
(0,687) \\
\end{array}$ & $\begin{array}{c}0,804 \\
(0,675) \\
\end{array}$ & $\begin{array}{c}0,789 \\
(0,660) \\
\end{array}$ & $\begin{array}{c}0,790 \\
(0,659) \\
\end{array}$ & $\begin{array}{c}0,708 \\
(0,644) \\
\end{array}$ \\
\hline Universidad & $\begin{array}{c}0,734 \\
(0,648)\end{array}$ & $\begin{array}{c}0,699 \\
(0,629)\end{array}$ & $\begin{array}{c}0,649 \\
(0,610)\end{array}$ & $\begin{array}{c}0,649 \\
(0,609)\end{array}$ & $\begin{array}{c}0,599 \\
(0,620)\end{array}$ \\
\hline \multicolumn{6}{|l|}{ Estatus laboral } \\
\hline Trabajador por cuenta ajena & ref. & ref. & ref. & ref. & ref. \\
\hline Desempleado & $\begin{array}{c}-0,787 * * \\
(0,332) \\
\end{array}$ & $\begin{array}{c}-0,757 * * \\
(0,328) \\
\end{array}$ & $\begin{array}{c}-0,778 * * \\
(0,325) \\
\end{array}$ & $\begin{array}{c}-0,779 * * \\
(0,327) \\
\end{array}$ & $\begin{array}{c}-0,789 * * \\
(0,329) \\
\end{array}$ \\
\hline Trabajador del sector público & $\begin{array}{l}-0,291 \\
(0,352)\end{array}$ & $\begin{array}{l}-0,323 \\
(0,349)\end{array}$ & $\begin{array}{l}-0,333 \\
(0,345) \\
\end{array}$ & $\begin{array}{l}-0,333 \\
(0,346) \\
\end{array}$ & $\begin{array}{l}-0,314 \\
(0,361)\end{array}$ \\
\hline Trabajador por cuenta propia & $\begin{array}{c}-0,775^{*} \\
(0,454)\end{array}$ & $\begin{array}{c}-0,778^{*} \\
(0,450)\end{array}$ & $\begin{array}{c}-0,768 * \\
(0,455)\end{array}$ & $\begin{array}{c}-0,767 * \\
(0,455)\end{array}$ & $\begin{array}{l}-0,724 \\
(0,464)\end{array}$ \\
\hline
\end{tabular}




\section{CUADRO 3 (Continuación)}

\section{SEGUNDA ETAPA DEL MODELO HURDLE: DETERMINANTES} DE LA CANTIDAD DONADA (ENTRE QUIENES DONAN)

\begin{tabular}{|c|c|c|c|c|c|}
\hline Variables & (1) & (2) & (3) & (4) & (5) \\
\hline Pensionista & $\begin{array}{l}-0,148 \\
(0,548)\end{array}$ & $\begin{array}{l}-0,205 \\
(0,547)\end{array}$ & $\begin{array}{l}-0,247 \\
(0,560)\end{array}$ & $\begin{array}{l}-0,246 \\
(0,558)\end{array}$ & $\begin{array}{l}-0,202 \\
(0,586)\end{array}$ \\
\hline \multicolumn{6}{|l|}{ Ingresos } \\
\hline Primer cuartil & $\begin{array}{c}0,196 \\
(0,335)\end{array}$ & $\begin{array}{c}0,171 \\
(0,332)\end{array}$ & $\begin{array}{c}0,165 \\
(0,334)\end{array}$ & $\begin{array}{c}0,169 \\
(0,333)\end{array}$ & $\begin{array}{c}0,153 \\
(0,338)\end{array}$ \\
\hline Segundo cuartil & $\begin{array}{l}-0,172 \\
(0,329)\end{array}$ & $\begin{array}{l}-0,162 \\
(0,320)\end{array}$ & $\begin{array}{l}-0,153 \\
(0,328)\end{array}$ & $\begin{array}{l}-0,153 \\
(0,327)\end{array}$ & $\begin{array}{l}-0,150 \\
(0,334)\end{array}$ \\
\hline Tercer cuartil & $\begin{array}{c}-0,101 \\
(0,295)\end{array}$ & $\begin{array}{l}-0,069 \\
(0,286)\end{array}$ & $\begin{array}{l}-0,059 \\
(0,285)\end{array}$ & $\begin{array}{l}-0,058 \\
(0,285)\end{array}$ & $\begin{array}{c}-0,078 \\
(0,289)\end{array}$ \\
\hline Cuarto cuartil & ref. & ref. & ref. & ref. & ref. \\
\hline Contribución alta & $\begin{array}{c}-0,507 * \\
(0,296)\end{array}$ & $\begin{array}{c}-0,487 * \\
(0,293)\end{array}$ & $\begin{array}{c}-0,502^{*} \\
(0,290)\end{array}$ & $\begin{array}{c}-0,505^{*} \\
(0,292)\end{array}$ & $\begin{array}{c}-0,522 * \\
(0,290)\end{array}$ \\
\hline No creyente & $\begin{array}{l}-0,273 \\
(0,255)\end{array}$ & $\begin{array}{l}-0,237 \\
(0,250)\end{array}$ & $\begin{array}{l}-0,257 \\
(0,249)\end{array}$ & $\begin{array}{l}-0,256 \\
(0,248)\end{array}$ & $\begin{array}{c}-0,242 \\
(0,250)\end{array}$ \\
\hline \multicolumn{6}{|c|}{ Variables preferencias sociales } \\
\hline Envidia & & $\begin{array}{c}0,031 \\
(0,062)\end{array}$ & $\begin{array}{c}0,048 \\
(0,064)\end{array}$ & $\begin{array}{c}0,049 \\
(0,064)\end{array}$ & $\begin{array}{c}0,050 \\
(0,066)\end{array}$ \\
\hline Compasión & & $\begin{array}{c}0,120 * * \\
(0,050)\end{array}$ & $\begin{array}{c}0,117 * * \\
(0,051)\end{array}$ & $\begin{array}{c}0,116^{* *} \\
(0,050)\end{array}$ & $\begin{array}{c}0,111^{* *} \\
(0,049)\end{array}$ \\
\hline Reciprocidad positiva & & & $\begin{array}{c}0,027 \\
(0,047)\end{array}$ & $\begin{array}{c}0,026 \\
(0,049)\end{array}$ & $\begin{array}{c}0,028 \\
(0,049)\end{array}$ \\
\hline Reciprocidad negativa & & & $\begin{array}{l}-0,099 \\
(0,061)\end{array}$ & $\begin{array}{l}-0,098 \\
(0,063)\end{array}$ & $\begin{array}{l}-0,104 \\
(0,068)\end{array}$ \\
\hline Altruismo & & & & $\begin{array}{c}0,009 \\
(0,063)\end{array}$ & $\begin{array}{c}0,008 \\
(0,062)\end{array}$ \\
\hline \multicolumn{6}{|l|}{ Variable capital social } \\
\hline Confianza & & & & & $\begin{array}{c}-0,312 \\
(0,317)\end{array}$ \\
\hline Justicia & & & & & $\begin{array}{c}0,143 \\
(0,227)\end{array}$ \\
\hline Constante & $\begin{array}{c}7,133 * * * \\
(1,041)\end{array}$ & $\begin{array}{c}6,634 * * * \\
(1,044)\end{array}$ & $\begin{array}{c}7,099 * * * \\
(0,991)\end{array}$ & $\begin{array}{c}7,057 * * * \\
(1,009)\end{array}$ & $\begin{array}{c}7,110 * * * \\
(1,015)\end{array}$ \\
\hline Observaciones & 792 & 792 & 792 & 792 & 792 \\
\hline
\end{tabular}

NOTA: Errores robustos entre paréntesis. $* * * p<0.01 . * * p<0.05 . * p<0.1$.

FUENTE: Elaboración propia. 
Respecto a las preferencias sociales, observamos que el componente $\beta$ (Compasión) del modelo de Fehr-Schmidt está positivamente relacionado con la decisión de donar. Aunque el diseño del juego del dictador elimina cualquier elemento de reciprocidad de la interacción, encontramos que los sujetos con mayor reciprocidad negativa tienen menor probabilidad de donar. Sería interesante desentrañar en futuras investigaciones por qué y a través de qué canales la reciprocidad puede tener efecto sobre las donaciones anónimas en el juego del dictador. Finalmente, las personas más altruistas tienen mayor probabilidad de donar en el juego.

Por último, respecto a las variables de capital social, las personas que consideran que el sentido de la justicia está extendido entre la sociedad son más proclives a donar.

A continuación se comentan los resultados encontrados para las regresiones que modelizan la cantidad donada, una vez se ha decidido donar (Cuadro 3).

En relación a las variables sociodemográficas, la variable edad es significativa y tiene un efecto cuadrático (forma de U invertida) a la hora de explicar la cantidad donada. Según los coeficientes estimados, los 49 años es aproximadamente la edad a la que más cantidad se dona. Este resultado es coherente con lo encontrado en Engel (2011): el valor modal entre personas de mediana edad es el reparto equitativo. Los hombres, una vez que deciden donar (a lo que son ligeramente menos proclives, según los resultados anteriores), donan más cantidad que las mujeres. El estatus laboral también afecta a la cantidad donada: desempleados y trabajadores por cuenta propia donan menos cantidad que los trabajadores por cuenta ajena. Y, por último, la contribución del individuo a los ingresos del hogar está asociada negativamente con la cantidad donada; si la contribución del individuo es alta menos cantidad donará.

Respecto a los dos bloques restantes, preferencias sociales y capital social, la única variable que aparece positivamente asociada a la cantidad donada es el componente $\beta$ del modelo de Fehr-Schmidt (Compasión).

En resumen, como se ha visto, los factores asociados a la decisión de donar y la cantidad donada no son los mismos. Incluso hay variables que afectan significativamente a ambas decisiones pero en direcciones opuestas. Mientras que los hombres tienen ligeramente menos probabilidad de realizar una donación, cuando deciden hacerla donan mayores cantidades que las mujeres. Este efecto contradictorio del género en las donaciones del juego del dictador también fue resaltado por Andreoni y Vesterlund (2001) y podría explicar por qué los estudios anteriores, que usan la donación total en el juego como medida de generosidad (sin diferenciar las dos etapas analizadas aquí), obtienen resultados mixtos. La responsabilidad sobre los ingresos del hogar también se asocia con distinto signo en ambas decisiones. Mientras que una contribución alta a los ingresos está asociada positivamente con la probabilidad de donar, su relación con la cantidad donada es negativa.

Finalmente, solo la compasión del modeloFehr-Schmidt predice significativamente ambas decisiones en la misma dirección: las personas más compasivas son más proclives a donar y, además, donan cantidades mayores. Esto concuerda con los resultados de Espín et al. (2018). 


\section{Conclusiones}

El juego del dictador es un entorno perfecto para estudiar el comportamiento generoso. La gran mayoría de los estudios publicados sobre este tema se han realizado utilizando muestras formadas por estudiantes universitarios. En nuestro trabajo, la heterogeneidad y representatividad de la muestra de la que disponemos, formada no solo por estudiantes, nos permite aportar a la literatura resultados sobre el papel de las características sociodemográficas, aparte de las preferencias sociales, en el comportamiento generoso. Otra característica poco habitual en los estudios sobre el comportamiento generoso es la metodología econométrica que se ha utilizado. Mediante modelos Hurdle se ha puesto de manifiesto que los mecanismos que trabajan sobre la decisión de donar y sobre la decisión de qué cantidad donar no siempre están asociados a los mismos determinantes. En esta línea, dado que la literatura anterior no ha analizado en profundidad las donaciones como un proceso de decisión en dos etapas (Engel, 2011), los resultados que se presentan aquí son novedosos, aunque en algunos casos sean coherentes con lo que se ha encontrado en estudios anteriores.

La decisión de donar está positivamente asociada a las siguientes características sociodemográficas: ser mujer, ser una persona divorciada (en comparación con soltera), pertenecer a familias con ingresos en el primer o el tercer cuartil (en comparación con las familias más ricas) y una alta contribución (mitad o más) a los ingresos del hogar.

Respecto a las preferencias sociales, los sujetos con mayor aversión a la desigualdad, en su componente de compasión (aversión a la desigualdad «ventajosa»), tienen mayor propensión a decidir donar. Es decir, se espera que individuos preocupados por el bienestar de los que se encuentran en peor situación que ellos no se queden con la totalidad del dinero. De igual forma, el altruismo está asociado positivamente a la decisión de donar. Por el contrario, la reciprocidad negativa está relacionada con una menor probabilidad de donar. Parece que las personas propensas a reaccionar negativamente cuando son tratados mal tienden a comportarse de manera poco generosa, aunque en principio la reciprocidad debiera, por diseño, no tener impacto en este juego. Este parece un resultado digno de ser estudiado en mayor profundidad en el futuro.

Respecto a las variables de capital social, las personas que creen que se hallan en una sociedad justa tienen mayor probabilidad de donar, les es más fácil ser generosos con extraños.

Los determinantes asociados a la cantidad donada una vez que se decide donar pertenecen principalmente a las características sociodemográficas de los individuos: edad (con un efecto cuadrático en forma de U invertida), ser hombre (con relación positiva), ser desempleado o trabajador por cuenta propia (que donan menos cantidad que los trabajadores por cuenta ajena), y tener una alta contribución a los ingresos del hogar (relación negativa). 
Aparte de las características sociodemográficas, los individuos con mayor aversión a la desigualdad en su componente de compasión donan más, una vez que deciden hacerlo. Esta es la única variable que afecta a ambas partes del proceso de decisión (donar y cuánto donar) de la misma forma. No en vano, quien toma la decisión en el juego del dictador parte de una situación relativa ventajosa respecto al receptor, por lo que parece razonable que las personas compasivas que sufren por obtener mayores beneficios que otras personas se muestren más generosas en el juego.

En conclusión, si se pretende entender y aprovechar las razones que llevan a las personas a ser generosas, nuestros resultados indican que debe tenerse en cuenta que los mecanismos que les pueden llevar a participar no siempre son los mismos que los que les pueden llevar a aumentar su participación. Estos resultados, por tanto, pueden ser de gran interés para las organizaciones y actividades que se nutren de la participación voluntaria de terceros.

\section{Referencias bibliográficas}

Andreoni, J., \& Vesterlund, L. (2001). Which is the fair sex? Gender differences in altruism. Quartely Journal of Economics, 116(1), 293-312.

Brañas-Garza, P. (2006). Poverty in Dictator Games: Awakening Solidarity. Journal of Economic Behavior \& Organization, 60(3), 306-320.

Brañas-Garza, P., Espinosa, M. P., \& García-Muñoz, T. (2009). Expectativas sobre comportamiento egoísta. Cuadernos Económicos de ICE (77), 33-43.

Brañas-Garza, P., Cobo-Reyes, R., Espinosa, M. P., Jiménez, N., Kovarik, J., \& Ponti, G. (2010). Altruism and Social Integration. Games and Economic Behavior, 69(2), 249-257.

Brañas-Garza, P., Cobo-Reyes, R., Espinosa, M. P., Jiménez, N., Kovarik, J., \& Ponti, G. (2012). Prosocial norms and degree heterogeneity in social networks. Physica A: Statistical Mechanics and its Applications, 391(3), 849-853.

Brañas-Garza, P., Capraro, V., \& Rascon-Ramirez, E. (2018). Gender differences in altruism on Mechanical Turk: Expectations and actual behaviour. Economics Letters, 170, 19-23.

Brañas-Garza, P., Jorrat, D., \& Espín, A. M. (2020). Envy, guilt and giving (Mimeo).

Burnham, T. C. (2003). Engineering altruism: a theoretical and experimental investigation of anonymity and gift giving. Journal of Economic Behavior \& Organization, 50(1), 133-144.

Camerer, C. (2003). Behavioral Game Theory: Experiments on Strategic Interaction. Princenton University Press.

Cragg, J. (1971). Some statistical models for limited dependent variables with application to the demand for durable goods. Econometrica, 39(5), 829-844.

Croson, R., \& Gneezy, U. (2009). Gender Differences in Preferences. Journal of Economic Literature, 47(2), 1-27.

Charness, G., \& Gneezy, U. (2001). What's in a name? Anonymity and social distance in dictator and ultimatum games. Journal of Economist Behavior \& Organization, 68(1), 29-35.

Eckel, C., \& Grossman, P. (1998). Are women less selfish than men? Evidence from dictator experiments. The Economic Journal, 108(448), 726-736. 
Engel, C. (2011). Dictator games: A meta study. Experimental Economics 14(4), 583-610.

Erkal, N., Gangadharan, L., \& Nikiforakis, N. (2011). Relative earnings and giving in a realeffort experiment. American Economic Review, 101, 3330-3348.

Espín, A.M., Moreno-Herrero, D., Sánchez-Campillo, J., \& Martín, J.A.R. (2018). Do envy and compassion pave the way to unhappiness? Social preferences and life satisfaction in a Spanish city. Journal of Happiness Studies, 19(2), 443-469.

Exadaktylos, F., Espín, A.M., \& Brañas-Garza, P. (2013). Experimental subjects are not different. Scientific Reports, 3, 1213.

Fehr, E., \& Fischbacher, U. (2002). Why social preferences matter: the impact of non-selfish motives on competition, cooperation and incentives. The Economic Journal, 112(478), C1-C33.

Fehr, E., \& Schmidt, K.M. (1999). A theory of fairness, competition, and cooperation. The Quarterly Journal of Economics, 114(3), 817-868.

Frohlich, N., Oppenheimer, J., \& Moore, J.B. (2001). Some doubts about measuring selfinterest using dictator games: the cost of anonymity. Journal of Economic Behavior \& Organization, 46(3), 271-290.

Henrich, J., McElreath, R., Barr, A., Ensminger, J., Barrett, C., Bolyanatz, A., Cárdenas, J. C., Gurven, M., Gwako, E., Henrich, N., Lesorogol, C., Marlowe, F., Tracer D., \& Ziker, J. (2006). Costly Punishment across Human Societies. Science, 312(5781),17671770.

Henrich, J., Ensimger J., McElreath, R., Barr, A., Barrett, C., Bolyanatz, A., Cárdenas, J.C., Gurven, M., Gwako, E., Henrich, N., Lesorogol, C., Marlowe, F., Tracer, D., \& Ziker, J. (2010). Markets, Religion, Community Size, and the Evolution of Fairness and Punishment. Science, 327(5972), 1480-1484.

Hoffman, E., McCabe, K., \& Smith, V. (1996). Social distance and other-regarding behavior in dictator games. American Economic Review, 86(3), 653-660.

Moffat, P.G. (2016). Experimetrics. Econometrics for experimental economics. Palgrave.

Perugini, M., Galluci, M., Presaghi, F., \& Ercolani, A.P. (2003). The personal norm of reciprocity. European Journal of Personality, 17(4), 251-283. 